\title{
The Learning by Discovery Guided: Implementation in a Framework for the Training of Future Trainers in Civil Engineering
}

\author{
Hajer Ben Amor ${ }^{1}$, Alia Maaloul ${ }^{2}$ \\ ${ }^{1}$ Higher Institute of Technological Studies, Rades, Tunisia \\ ${ }^{2}$ Higher Institute of Technological Studies, Gabes, Tunisia \\ Email: hejer.benamor@yahoo.fr,maaloul.alia@gmail.com
}

Received 21 January 2016; accepted 14 March 2016; published 17 March 2016

Copyright (C) 2016 by authors and Scientific Research Publishing Inc.

This work is licensed under the Creative Commons Attribution International License (CC BY). http://creativecommons.org/licenses/by/4.0/

(c) (i) Open Access

\begin{abstract}
The main objective of a training program for future trainers Guineans, specialized and competent in Civil Engineering in training centers in their countries, is to use a new method of teaching by guided discovery in the framework of the course of Civil Engineering structures. In this context, a learning study was considered and put in application for the Higher Institute of Technological studies of Rades since November 2015 for a number of hours equal to 90 . This innovative project brings together several aspects in Civil Engineering which are addressed through an analysis of a real case. The adopted approach is to apprehend a visit upstream of the teacher of the course in order to master the components of the job site to visit. Consequently, a guided tour of the students is programmed and provided by their teacher. The obtained results are satisfactory on the side of the learners in the field of learning, pedagogical innovation, motivation and profitability. However, these results remain still perfectible.
\end{abstract}

\section{Keywords}

Civil Engineering, Pedagogical Innovation, Learning by Discovery Guided, Motivation

\section{Introduction}

Like many other sectors, the world of research and higher education now lives a massive trend to "innovation”.

How to cite this paper: Amor, H. B., \& Maaloul, A. (2016). The Learning by Discovery Guided: Implementation in a Framework for the Training of Future Trainers in Civil Engineering. Creative Education, 7, 453-461. 
The term Innovation replaces, nowadays, what is previously called "progress (Hamida et al., 2016).

In the institutions of higher education and more particularly in the higher institutes of Technological Studies (ISETs), object of this work, this orientation aims, on the one hand, to better guide the research toward the transfer of knowledge in the direction of professional organizations: Offices of Studies, Businesses, Master of Books... and even more profitable the corresponding applications. On the other hand and in the same axis of innovation, efforts are developed to generate a consistent correlation to adapt the lessons learned to the expectations of students in regards to the world of work and to meet the new requirements which are necessary for professional and industrialists environments.

As well the pedagogical innovation is becoming a general imperative, not only for the trainers but also for teachers, and responding to the need to adapt their training to the requirements of the market.

However, this trend to the pedagogical innovation has effects on the educational mission of the teacher and it is confronted with the obligation to update its teaching methods and to adopt a contemporary training. The latter is related to the obligation to develop knowledge and know - how to allow the socialization of the learners and the gradual construction of their professional identities, in particular through their involvement in the actual situations of the professional world (Bollen et al., 2015).

The work presented in this rapport describes and spreads the modalities of an experimentation of a new pedagogical strategy proposed in respect of the interests and contributions of the discovery tour.

The learners concerned by this study are Equato-Guineans. They are intended to be trainers in vocational training centers of Civil Engineering in their country. The training of these future trainers is held to the ISET of Rades-Tunisia.

In what follows, we will explain a theoretical foundation of a proposed strategy and an expounded surgical approach about the execution and we will also represent some results of its implementation and the continuous improvements that it raises.

\section{Context and Problematic}

The guided discovery is a pedagogical approach offering the possibility to the learner to fictively exercise its prerogatives for the future trainers in professional training centers in the Equato-Guinée.

This pedagogical innovation is a priority subject for several improvements that contribute to highlight the theoretical knowledge acquired in training room.

This dynamic and continuous learning allows each learner to discover and famliariser more with real projects of civil engineering and start grinding and developing their professional skills.

In fact, we are convinced to add a new value to this method experimented at ISET of Rades in 2015 on these learners who are the future trainers in vocational training centers specialty: Civil Engineering to the EquatoGuinée.

An implementation of this method in higher education takes various forms and raises several questions concerning: the target audience, the objectives, the modalities of the organization, the modalities of accompaniment, the appropriation by the learners, the modalities of the assessment...

\section{Learning by Guided Discovery}

"For there to be learning, there must be learn, love to learn and want to learn. The absence of one or the other of these dimensions leads very quickly a stop of the process” (Belbaum, 1996).

The usual and classics methods are deductive and based on a reasoning which goes from the general to the particular.

At this stage, the teacher presents first the course, and then proposes exercises application closest to the theory rather than to the reality in order to enhance memory and understanding (Bollen et al., 2015).

Although, the guided discovery that we propose is an innovative and educational strategy referenced to each individual experience for which our concepts were developed instead and not being transmitted, but also a method and a learning process for which the student can ask questions and try to answer.

Of this fact, the framework of the inductive methods, the purpose of the tested method is to discover, to clarify and to palpate and also mainly to constitute a mechanism of encouragement, guidance, discovery, of assistance and guidance for the learners in the course of their training.

Thus, an implicit correlation has emerged, between the discovery guided and the constructivism, of the fact 
that the learners exploit patterns of knowledge they have acquired in order to reach the progressive developments and to accomplish individualized restructuring of new knowledge personified schemes.

This method considers that the learner is an active subject, on the one hand, and on the other hand, it reacts in function of its environment composed of trainers, of the Working Group and also of the general context of the learning. Of this fact, one of the main concerns of the pedagogues of the new education consists in the integration of the learner within the method as an active component in the learning process.

The practices of this active pedagogy have been widely fed and sustained by the contributions of this constructivist psychology according to which the apprenticeships are no longer done by packaging but by building mental activities in interaction with the environment (Ganter et al., 2008).

\section{Practical Implementation of the Proposed Method}

The test of the proposed innovative pedagogical technique requires a definition of the framework for the integration of the method and a demarcation of the quality of the public concerned by the latter.

In addition, it would be important to present the methodological steps to be undertaken to highlight the progress of the operating mode of the said method. Of course, adjustments have been introduced, along the years of its implementation in tests, to arrive nowaday to a package well adapted for the use via a parameterization that is a function of availability and the general context.

\section{Framework and Target Audience}

The teaching of this subject relates a pilot group of twelve students Equato-Guineans, future trainers in vocational training centers in their countries, for the specialty Civil Engineering. In this particular framework, the course "Structures Engineering" is taught in the ISET of Rades for an hourly load of 90 hours.

The training acquired by the teaching of this course will be used to consolidate the common training of other programme courses, during the formation of these future trainers, such as construction technologies, technologies materials, technologies of public works, study of the works of buildings in concrete, roadway systems and various networks, conduct of the shipyards, takeoffs and study of price and also of the management control and monitoring of the work of shipyards...

\subsection{Procedure for Programming}

The operating mode is translated by the consecutive executions of the following actions:

- Reminder of the prerequisites and presentation of basic theoretical supports.

- Effective visits discovering real art structure sites.

- Collective works application for 3 hours, in small groups on real planes of a work of art.

-Reminder of the pre-requisite and presentation of theoretical medium base.

- Actual visits of discovery of the actual sites of building sites of work of art.

-Collective work of application of duration 3 hours, in small groups on real plans of a book of art.

\subsubsection{Pre-Requisite Support of the Basic Theory}

During each session, the subject is taught in close connection between the theory and the good practices of the professional life combined with a return of experience guaranteed. At this level the learner is subjected to a basic training on the concepts and the nomenclatures used widely in a yard. Examples of illustration, from experiences on other yards made, will be widely explained.

\subsubsection{Visit of Shipyards}

These visits are programmed to consolidate the theory already advanced. Of this fact, the teacher is required to master the details of the yard with preliminary visits to familiarization with the general context in order to collect the maximum of information on the project concerned. Thus, it is asked to:

-Identify its location, its different access, its environment, its hours of work and recognize the tracks that can be toured by visitors of the yard in any security.

-Estimate the duration of the displacement by the bus of the ISET up to the yard in order to estimate the du- 
ration of the visit and then anticipate the hours of departure and return of students.

- Identify the elements of books in the course of execution and the constructive modes applied.

Then when all these information are required, the teacher of the course "Bridges" accompanies the future trainers during the site visit, programmed beforehand, to fill the gaps that may arise in particular conditions. However, the responsible teacher is invited to remind and warn learners about the risks of the site.

\section{Session 1: Preparatory acts}

During this meeting, the teacher:

- Presents the project Site for the future trainers before the dates of the visit. In this context, the teacher is required to inform them on the different stakeholders, the types of project, the main tasks in the course of implementation, ..., in view to orient in advance on the axes of Their discoveries during the visit.

- Incites the future trainers to wear clothes adapted for a site assisting primarily a reaction comfortable with the ups and downs of the scaffolding stairs.

- Informs the future trainers that moving into one group, coherent and linked, is required and that this rule can not be fulfilled in certain specific situations visits.

\section{Session 2: Visit of shipyards}

The day of the visit, the teacher reminds the settlement of the visit before accessing to the site of the future trainers (on the bus or at the ISET before leaving).

The visit of the future trainers in the building site is carried out with a represent of the site and the responsible teacher at the ISET Rades to place more emphasis on the tasks performed and recorded events related link with the course of being taught.

Figure 1 shows the photo of the Equatorial Guinean students with their teacher and project manager on the deck of a bridge slab made of prestressed concrete being executed-project exchangers X2 channel in Tunis in November 2015. Figure 2 shows the photo of the same group with their teacher during a visit of the railway network project fast running, December 2015.

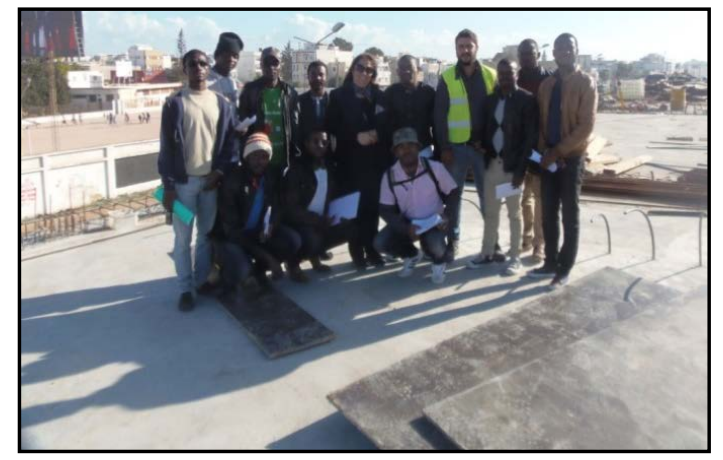

Figure 1. Project: Heat exchangers of the track X2 In Tunis November 2015.

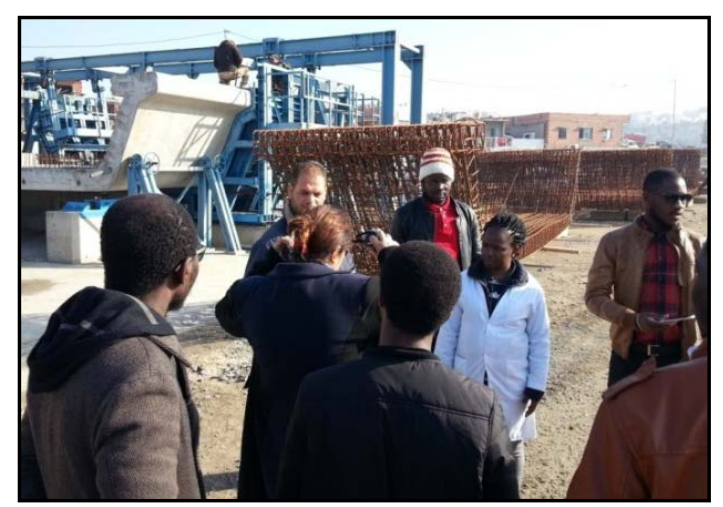

Figure 2. Visit the project Rail Network Quick in Running, December 2015. 


\section{Session 3: Assessments of students}

During this session of assessment, which happens in the classroom, each student must give the teacher a report on the visit. Some learners are designated by the teacher in the classroom to present a briefing on the visit, with a video projector to facilitate discussion.

In this context, the teacher proceeds to a series of questions to the learners on the visit to assess their presence of mind, their opinions and criticisms about the conduct of job site safety, skills, performance, applied technologies...

\section{Work on real plans}

The work is preferably during sessions of 3 hours and by subgroups constituted by 2 or 3 learners (Figure 3 ).

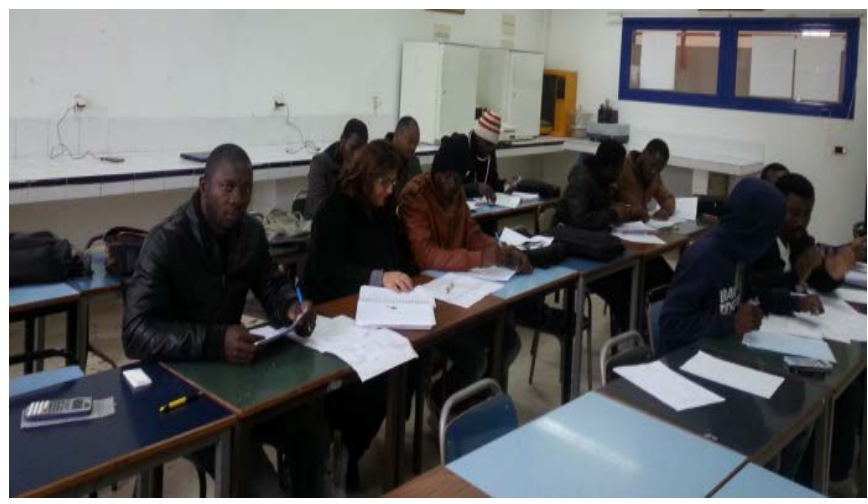

Figure 3. Work of students Equato-Guineans on real plans.

A series of real plans (preferably comprising several data on the site visit conducted or a similar site) is served to each sub-group with a series of questions to answer.

Example: A formwork plan on a deck of a bridge slab comprising the plan view, the transverse cut, the longitudinal cut and other explanatory details.

Work requested:

-Describe the content of the plans.

- Give the constituents and the dimensions of the various elements of the work presented (apron, stack, abutment, foundations).

-Appoint the equipment visible on the plans.

\section{Evaluation of the Experiment}

\subsection{Investigation of Evaluation}

This survey is to know the feedback of the learners who followed this training through guided discovery. It also aims to discern the degree of satisfaction of future trainers and their level of motivation on life in the building sites of structures. It can also give an idea about the limits of the new teaching method adopted in view to add any improvements.

To do this, we have developed a questionnaire that we distributed to the learners to collect their suggestions and comments will be analyzed and stored in the database. Eight questions were asked, the content rode around:

Q1-The assessment of a future trainer's satisfaction degree concerning the contributions of the course works of art.

Q2-The perception of students' motivation on the use of yard's visits.

Q3-The relativity of the tour guided's role on understanding the real plans of works of art.

Q4-The assessment of difficulties' degree of a ship yard of works of art.

Q5-The role of the guided tours added to the theory in the enrichment of the Know How to read plans of works of art.

Q6-The satisfaction degree of the expected results by the course works of art dispensed.

Q7-The effects of reading real plans and the site visits realized on the deep knowledge in works of art.

Q8-The possibility to manage individually a ship yard of works of art. 


\subsection{Analysis and Interpretation of the Results of the Investigation}

At completion of the training cycle of 90 hours, honored in favor of a promotion of 12 students Equatorial Guineans, we conducted a survey via a questionnaire proposed to the concerned. This is actually proceeding to assessing degree of satisfaction expressed by the results of the application of the new consolidation action of the theoretical teaching of the subject "Bridges" by assisted visit guided by the teacher of the subject.

We had obtained 10 responses out of 12 is a ratio of about $84 \%$ of the workforce involved in the training.

Figure 4 illustrates the results to the question "Q1" on the assessment of the degree of satisfaction of a trainer future of the contribution of the matter as a new studied matter. In fact, as a newly acquired matter for the concerned students, $80 \%$ as positive response rates is more than satisfied and seems to be acceptable. However, the $10 \%$ rate of unmet requires a sincere analysis to find out the causes.

Regarding the expectations of the learners, although the ratio of $90 \%$ of very well satisfied, which seems very encouraging, we consider that the ratio of $10 \%$ of less satisfied deserves to be elucidated, Figure 5.

The results presented in Figure 6 confirm that the guided visits to the underway projects were quite motivating for $100 \%$ of learners. Moreover, $10 \%$ of them describe these visits very motivating.

Moreover, the results in Figure 6 are consolidated with those in Figure 7, where learners express their agreement to $100 \%$ of the benefits of such visits on learning and understanding the real Bridges plans.

The students have classified the sites visited as easy despite the reduced number of the realised visits, Figure 8. $100 \%$ of the learners judge that such visits had helped them to make easy reading of real Bridges plans, Figure 9.

Also, $90 \%$ among certifies that the real plans' reading has contributed on deepening their knowledge in the field of "Bridges", Figure 10.

A particular attention is given to the results of Figure 11 which stipulates that the main objective, of this training of Equatorial Guinean learners, is to prepare them at the Formateur function in their countries. Moreover, such a function can only be efficient if the affected are able, to each, to manage himself a job site Bridges.

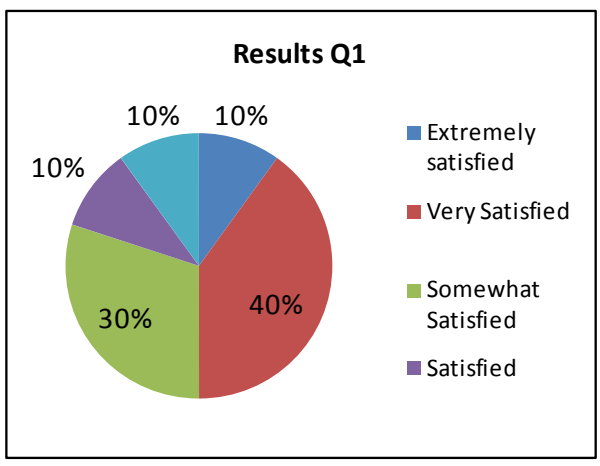

Figure 4. Satisfactiontoward the subject "Works of Art”.

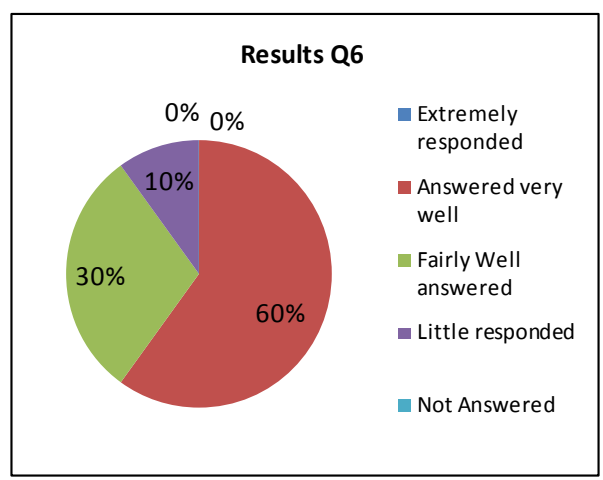

Figure 5. Satisfaction vis a vis the expected results. 


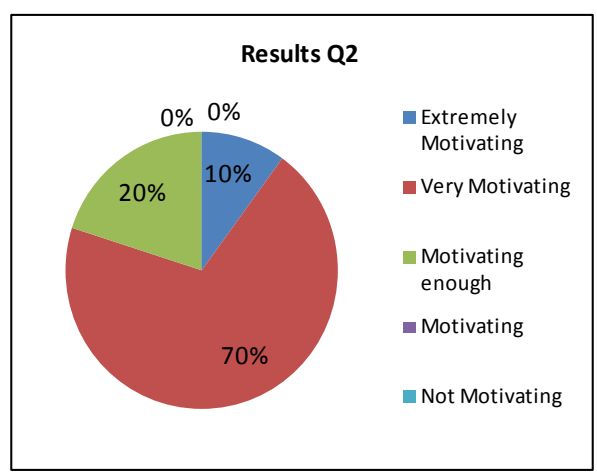

Figure 6. The perception of the motivation of the guided tours of learners by the visits of building.

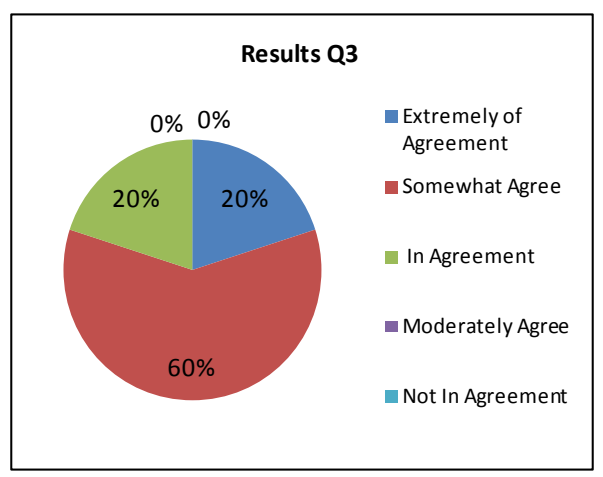

Figure 7. The relativity of the role of the construction in the understanding of the real plans of "Works of Art".

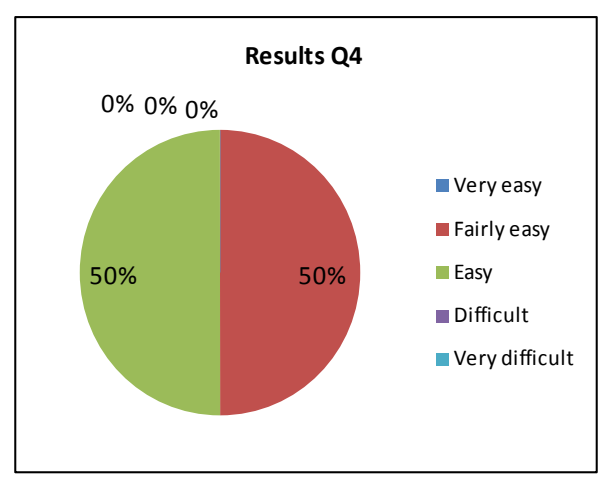

Figure 8. Degrees of difficulty of a yard of "Works of Art".

Figure 11 shows that only 50\% reported conclusive for oneself managing Bridges sites, against $20 \%$ who are inconclusive and $10 \%$ are non-conclusive.

\subsection{Review and Interpretation of the Results}

We believe that this new pedagogical modality is relevant and efficient in terms of skills and knowledge that could be acquired through its use. In addition, the use of the visits and the real plans' reading were the opportunity to introduce issues and professional situations which would not have been even addressed by either the discipline's issues or by cross-cutting ones. 


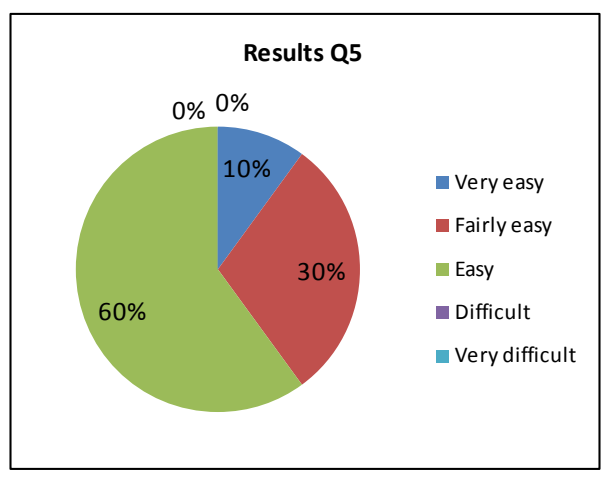

Figure 9. Reading difficulties of a real plan of "Works of Art".

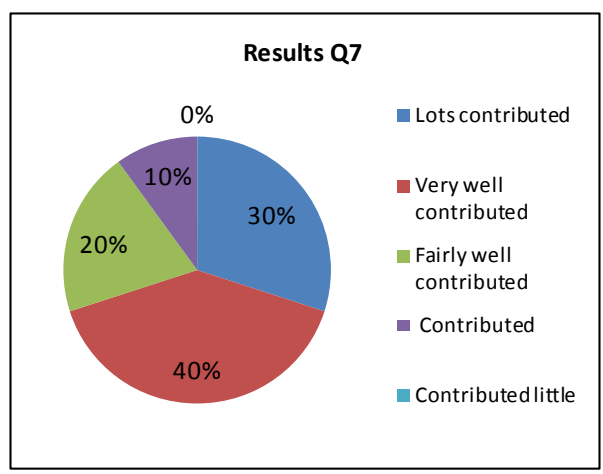

Figure 10. Deepening of knowledge in "Works of Art”.

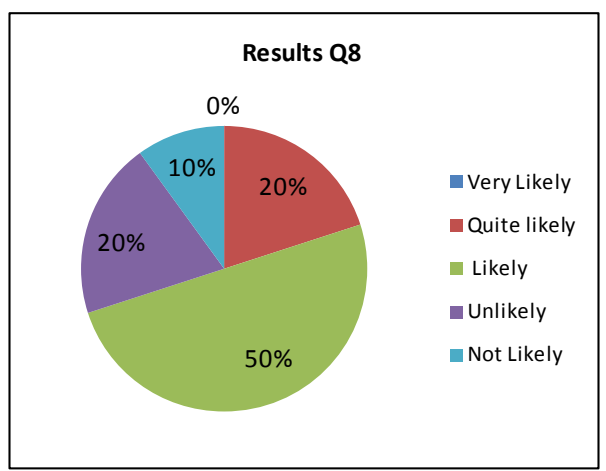

Figure 11. Possibility of management of a construction site of "Works of Art".

Besides, we can estimate that this experimentation presented a rich balance sheet in terms of both improving theoretical learning and emerging them on a real professional context.

It is important to notice that thanks to this experience, learners become very attached to the ship yards of works of art.

These results express the contribution of this innovative method; discovery guided, and seem to promote the progress and the mastery of the learning process.

From another side, we can notice that this experimentation's limits are essentially related to the organizational difficulties, the bureaucracy and logistical constraints.

The visit may sometimes overstay the programmed duration of three hours because of the distance between the site of the ISET. In addition, many visits have been cancelled due to climatic factors and logistics. 
In effect, this method allows the learner to construct their skills, to familiarize themselves with the World of Civil Engineering and thus is considered as the best way to give them confidence in themselves. This feeling will certainly be transmitted to their future students in the vocational training centers.

Overall, we believe that the guided visits provide an added value to the teaching of our discipline in a general way. This shows a real interest for a modality regarded as having a high potential for learning the future trainers despite the limitations perceived by the teachers.

Unfortunately, these limits are representative of the main concern of any teacher: the one to arrive to acquire his learners knowledge and skills and to ensure them about this (Konopka et al., 2015).

\section{Conclusion}

In this work, we integrate an innovative procedure based on discovery visits to provide to the taught course a correlation with the practice of the ship yards in Civil Engineering.

In comparison with the traditional teaching methods, this new one that we propose in this article leads to better results in terms of both acquired knowledge and learners' motivation.

Although the potential of this device innovative teaching is enormous and promising, it remains perfectible and present, in some cases, limitations of exploitation.

The implementation of this practice has helped to lead to the development of new pedagogical situations allowing students to build a professional identity in advance.

We consider that the obtained results are generally promising and can be enhanced through a logistic availability, a relief of administrative formalities, duration of visiting more spread out and especially suitable ethics teachers of this field.

\section{References}

Bollen, X., Ducarme, D., Galmiche, E., \& Raucent, B. (2015). Workshop: Tricycle against The Shows: The Team Work and the Development of Cross-Cutting Skills. Innovate: How and Why? Acts of the viiith Symposium of QPES 2015, BREST, 16-19 June 2015, 923-928.

Ganter, R., Lorentz, J. M., \& Philipps, C. (2008). The Educational Visit Company, Academy of Strasbourg.

Hamida, S. B., Maaloul, A., \& Hamida, S. B. (2016). The Pedagogical Innovation Serving Technological Education. Creative Education, 7, 20-31. http://dx.doi.org/10.4236/ce.2016.71003

Konopka, C. L., Adaime, M. B., \& Mosele, P. H. (2015). Active Teaching and Learning Methodologies: Some Considerations. Creative Education, 6, 1536-1545. http://dx.doi.org/10.4236/ce.2015.614154 